\title{
Field test on visibility at cycle crossings at night
}

\author{
Sara Nygårdhs • Carina Fors
}

Received: 30 April 2010 / Accepted: 28 July 2010 /Published online: 25 August 2010

(C) The Author(s) 2010. This article is published with open access at Springerlink.com

\begin{abstract}
Purpose The main purpose of the study was to compare the night-time visibility distance of cycle crossings to the nighttime visibility distance of bicyclists at the corresponding cycle crossings. This was tested both for dry and wet road surface.

Methods The test was carried out as a field study with twelve participants being passengers in an instrumented car. The test route included nine cycle crossings, that all were combined with pedestrian crossings. The participants individually pushed a noiseless button when they saw a dummy bicyclist standing still at a crossing, in part one, and when they saw a correctly marked cycle crossing in part two. Visibility distances to bicyclist dummies and cycle crossings were measured. Half of the participants experienced dry road surface and the other half wet road surface. An analysis of variance was conducted with a split plot design of group (wet / dry road surface) $\times$ target (bicyclist dummy / cycle crossing) $\times$ crossing ( 9 different cycle crossings).

Results The bicyclist dummies were detected at a significantly longer distance (mean $59.1 \mathrm{~m}$, standard error $2.9 \mathrm{~m}$ ) than the cycle crossings (mean $17.5 \mathrm{~m}$, standard error $1.0 \mathrm{~m}$ ). The road condition (wet/dry) only had an effect on the visibility of cycle crossings.

Conclusion The field test showed that bicyclists are seen at longer distances than cycle crossings combined with pedestrian crossings in Sweden at night-time.
\end{abstract}

Keywords Cycle crossing $\cdot$ Visibility $\cdot$ Night-time $\cdot$ Bicyclist

\section{Introduction}

In Sweden, about $25 \%$ of all bicycle accidents involving a motor vehicle occur at cycle crossings [1]. Swedish traffic

\footnotetext{
S. Nygårdhs $(\bowtie) \cdot$ C. Fors

Swedish National Road and Transport Research Institute, VTI, 58195 Linköping, Sweden

e-mail: sara.nygardhs@vti.se
}

rules state that bicyclists should yield to motorists at cycle crossings, except at roundabout exits and immediately after the motorist has turned in a crossing. In the two latter cases the driver has probably raised her/his level of attentiveness because of the roundabout/crossing and also reduced the speed. In a recent proposal from the Swedish Transport Agency [2], it is suggested that motorists should yield to bicyclists at all cycle crossings. It is thus of importance that the cycle crossings are designed in a way that the motorists will detect them on a distance where they will have time to scan the surroundings and stop if a bicyclist appears. Shorter visibility distances may involve higher accident rates.

It is shown by Fors and Lundkvist (2009) [3] that very little research on bicyclists in night-time traffic was reported during the years 1998-2008. Only two studies were of interest, dealing with lighting and reflector tags on bicycles. Lindahl and Stenbäck (1999) found that about 30\% of bicyclists in urban areas in Sweden are fully conspicuous, i.e. the bicycle has light at the front and at the rear and reflector tags on the sides [4]. In a focus group study on road users' needs and experiences of night-time traffic in urban areas, bicyclists, older pedestrians as well as older drivers were of the opinion that the visibility of bicyclists and cycle crossings is poor [5]. The estimated bicyclist accident risk in Swedish urban areas (based on police reported injury accidents in official accident statistics) is increased by $42 \%$ in darkness compared to in daylight, according to Johansson and colleagues [6]. For Sweden, Norway and the Netherlands in total, the risk is increased by $52 \%$.

Hence, accident risk and darkness are closely connected to each other. The visibility in darkness is naturally poorer than in daylight. Visibility can also be affected by the road condition, i.e. if the road surface is dry or wet or if the contrast between the target and the background is high or low. Previous experience shows that the visibility of dry road markings is better than of wet road markings $[7,8]$. 
The aim of this study was to compare the night-time visibility distance of cycle crossings to the night-time visibility distance of bicyclists at the corresponding cycle crossings. This was tested both for dry and wet road surface.

\subsection{Cycle crossings in Sweden}

The Swedish Road Administration states that a cycle crossing can be marked on a place meant to be used by bicyclists or moped riders (riding a moped class II) to cross a road or a cycleway [9]. The cycle crossing should be designed with white road markings in the form of squares with each side $0.5 \mathrm{~m}$ long. The cycle crossing can be combined with a pedestrian crossing as shown in Fig. 1.

\section{Method}

The study was conducted as a field test during the dark hours (11 PM-05 AM) in October 2009 in the city of Norrköping in Sweden.

\subsection{Participants}

Twelve participants, six males and six females, were recruited for the study. They all had a driving licence and none of them were familiar with the city of Norrköping, with the exception of sporadic visits. The age of the participants ranged between 26 and 57 years and they had self-reported normal or corrected vision.

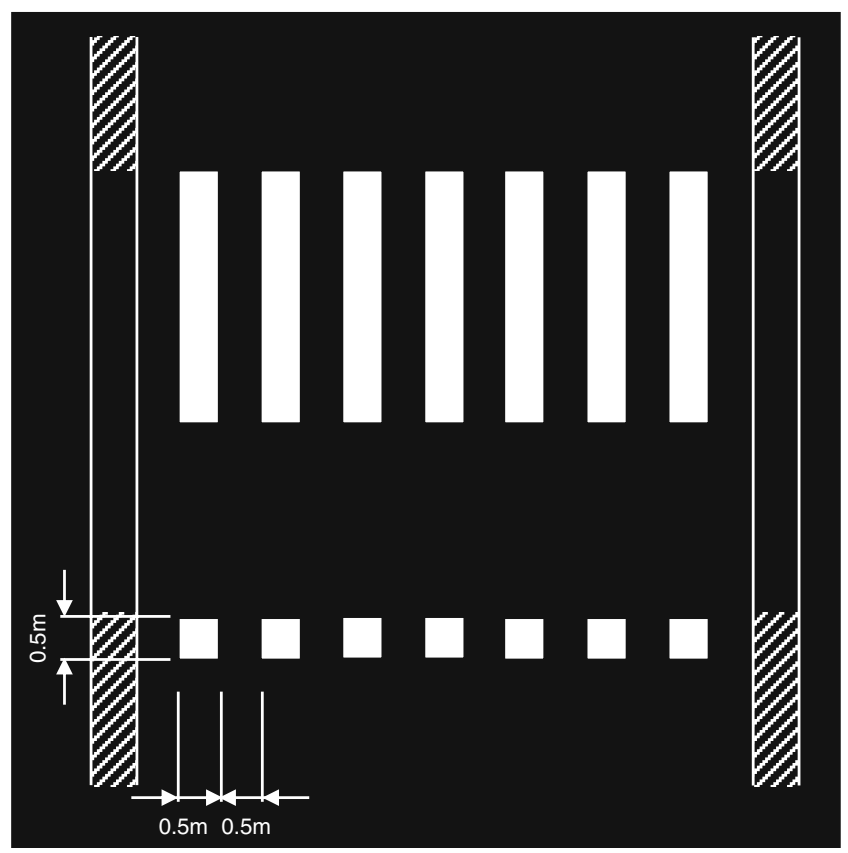

Fig. 1 Example of road marking at a cycle crossing combined with a pedestrian crossing

\subsection{Test route}

A route of approximately $10 \mathrm{~km}$ was used as a test route. The test route was located in urban areas and included nine cycle crossings and two starting positions. The posted speed limit was $50 \mathrm{~km} / \mathrm{h}$ along the entire route. All nine cycle crossings were combined with pedestrian crossings (as in Fig. 1) and located on straight roads, i.e. cycle crossings at exits of roundabouts or immediately after turns were excluded.

\subsection{Instrumented car}

The car used in the experiment was a Volvo 855 with logging equipment. Four noiseless push-buttons were linked to a computer. The computer registered the exact time for each push-button being pushed down. The driver (i.e. the test leader) pushed his button each time a cycle crossing was passed. The participants were passengers who individually pushed their push-buttons when they detected a bicyclist dummy or cycle crossing, respectively. Vehicle speed was also logged and thereby the distance travelled between two buttons being pushed down (i.e. a participant's and the driver's) could be computed.

\subsection{Task}

The participants sat as passengers in the instrumented car; either in the front passenger seat, in the centre rear seat or in the right rear seat. The experiment was separated into two parts with a break in between. Each participant sat on the same seat during the whole experiment. In the first part, the participants were required to push a noiseless button when they saw a dummy bicyclist at a crossing, waiting to pass the road (see below). A written instruction was handed out for the participants before the first part, containing a photo of a bicyclist dummy and instructing the participants only to push the push-button when they were certain that there was a bicyclist dummy. They were also verbally briefed about the task and directed to test the push-button to see how it worked.

When part 1 of the experiment was complete, the bicyclist dummies were removed. In the second part of the experiment, the task for the participants was to push the button when they were certain that they saw a cycle crossing - correctly marked with squares - on the road on which they were travelling. They were given a written instruction and a picture informing them of how a cycle crossing is supposed to look before the second part began. The participants were also informed that all of the cycle crossings in the test route were combined with pedestrian crossings but that not all of the pedestrian crossings were combined with cycle crossings. It was emphasized that the 
participants should only push the button when they saw the road marking squares connected to the cycle crossing, i.e. only to see the pedestrian crossing was not enough to provoke any push.

The bicyclist dummies in part 1 were placed at exactly the same cycle crossings used in part 2, but this was not known by the participants. To minimize the expectations of the participants, the first part began at one starting position, while the second part began at another starting position. There were approximately 90 min between part 1 and part 2.

\subsection{Dummy bicyclists}

Nine identical dummy persons had been made from a silhouette of an outdoor-dressed person. The dummy persons were painted in matt grey colour with a luminance factor of 0.28 . They were $170 \mathrm{~cm}$ high, $37 \mathrm{~cm}$ wide at the widest part and $1 \mathrm{~cm}$ thick.

To create bicyclist dummies, each dummy person was placed on the ground next to a bicycle and was attached to the bicycle by thin black cable ties. The bicycles differed in height, colour and shape, but most of them were dark. The reflection tags on the wheels of the bicycles were concealed with blue tape. A bicyclist dummy standing at a cycle crossing is shown in Fig. 2.

The bicyclist dummies were always placed at a cycle crossing and at the right-hand side of the road, standing as if they were about to cross the road.

\subsection{Experimental design}

The variable measured in the experiment was visibility distance, both to the bicyclist dummies and to the cycle crossings. The experiment was conducted for two conditions: dry and wet road surface. The wet road surface condition was obtained in connection to a rainfall. However, there was no rain during the runs in

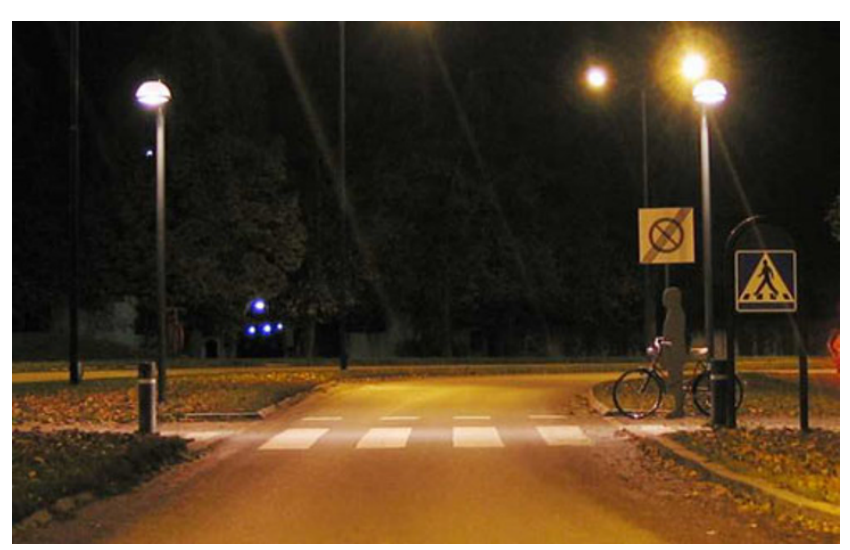

Fig. 2 Dummy bicyclist standing at a cycle crossing the experiment. Six of the twelve participants participated in each condition. Table 1 summarizes the experimental design.

\subsection{Photometric measurements}

Some descriptive physical parameters related to visibility of bicyclist dummies and cycle crossings were included in the study. The contrast $C$ between the road surface and marking was calculated as:

$C=\frac{L_{\text {roadmarking }}-L_{\text {roadsurface }}}{L_{\text {roadsurface }}}$

where $L_{\text {roadsurface }}$ is the mean value of the luminance at the road surface in front of the centre and the right road marking square of the cycle crossing from the car driver's point of view, and $L_{\text {roadmarking }}$ is the mean value of the luminance at the centre and right road marking square of the cycle crossing from the car driver's point of view. The luminance $L$ at each position was calculated as:

$L=Q d \cdot E$

where $Q d$ is the daylight luminance coefficient and $E$ is the illuminance. $E$ and $Q d$ were measured with handheld instruments in connection to the field study.

The perpendicular illuminance at the dummy bicyclist's head was measured both at the front and at the back side, and the difference between these two measures, $\Delta E$, was calculated.

\subsection{Data analysis}

An analysis of variance, ANOVA, was conducted with a split plot design of group $(2) \times \operatorname{target}(2) \times$ crossing $(9)$. The between-subjects factor was the two groups performing their tasks in the dry and wet road surface condition, respectively. The repeated measures factors (within-subjects) were the two detection targets, i.e. the bicyclist dummy and cycle crossing, and the nine crossings.

In addition, two separate analyses of the visibility of cycle crossings and bicyclist dummies, respectively, were carried out, with respect to road surface condition, i.e. a mixed design ANOVA of group (2) $\times$ crossing (9). These analyses were performed due to the expected effect of road surface condition on the visibility of cycle crossings.

If the assumption of sphericity was violated, the degrees of freedom were corrected, using the GreenhouseGeisser correction. A $p$-value of $<0.05$ was considered as significant.

Missing values in the data set were replaced by their condition mean values. 
Table 1 Experimental design

\begin{tabular}{|c|c|c|c|}
\hline \multicolumn{2}{|c|}{ Road surface condition } & \multirow{2}{*}{$\begin{array}{l}\text { Participants } \\
n=6 \text { ( } 3 \text { male, } 3 \text { female })\end{array}$} & \multirow{2}{*}{$\begin{array}{l}\text { Target } \\
\text { Part 1: } 9 \text { bicyclist dummies } \\
\text { Part 2: } 9 \text { cycle crossings }\end{array}$} \\
\hline Test group 1 & Wet road surface & & \\
\hline Test group 2 & Dry road surface & $n=6$ ( 3 male, 3 female $)$ & $\begin{array}{l}\text { Part 1: } 9 \text { bicyclist dummies } \\
\text { Part 2: } 9 \text { cycle crossings }\end{array}$ \\
\hline Total & 2 road surface conditions & 12 participants & 9 cycle crossings, with and without bicyclist dummy \\
\hline
\end{tabular}

Occasionally the participants pushed the button more than once while approaching a cycle crossing. In those cases, only the last registration was included in the analysis.

\section{Results}

The ANOVA showed main effects of target, $F(1,10)=$ $59.12, p<.0001$, and crossing, $F(8,80)=12.05, p<.0001$. Table 2 contains the full ANOVA. There were $1.85 \%$ missing values (4 out of 216) and each was replaced by its condition mean value. Because of a violated sphericity assumption, Greenhouse-Geisser corrected $p$-values were reported.

There was an interaction effect of target and crossing, $F$ $(8,80)=8.76, p<.0001$. While the bicyclist dummy was detected at a distance farther away compared with detection of cycle crossing for all crossings, the interaction effect shows that this difference in detection distance varies over crossings. This is illustrated in Fig. 3. The average visibility distance of bicyclist dummies was $59.1 \pm 2.9 \mathrm{~m}$ (mean \pm standard error) while the visibility distance of cycle crossings was $17.5 \pm 1.0 \mathrm{~m}$. Figure 3 also shows the stopping distance when driving in $50 \mathrm{~km} / \mathrm{h}$, assuming a reaction time of $1 \mathrm{~s}$ followed by full brake (approximately 26 and $28 \mathrm{~m}$ for dry and wet road surface, respectively) [10].

There was no interaction effect between group (road surface condition) and target. However, separate analyses of road surface condition showed that cycle crossings were detected at a significantly longer distance $(p=0.030)$ on dry roads $(20.9 \pm 1.5)$ than on wet roads $(14.1 \pm 1.2)$. No such effect was observed for bicyclist dummies $(p=0.797)$.

Figures 4 and 5 show the mean visibility of cycle crossings and bicyclist dummies, respectively, on wet and dry roads.

Figure 6 shows the results of the photometric measurements: Fig. 6a shows the difference, $\Delta E$, between the perpendicular illuminance measured at the front and back side of the dummy bicyclist's head in relation to the visibility distance of the bicyclist dummy. Figure $6 \mathrm{~b}$ shows the contrast, $C$, between the road surface and road marking at the cycle crossing in relation to the visibility distance of the cycle crossing.

The photometric measurements indicated no clear relation between visibility and $\Delta E$ (for bicyclist dummies) or $C$ (for cycle crossings).

Table 2 ANOVA with mixed design of group, target and crossing

\begin{tabular}{|c|c|c|c|c|c|c|c|}
\hline Effect & $\mathrm{SS}$ & df & MS & $\mathrm{F}$ & $p$-value & corrected $p$-value & effect size $\eta_{p}{ }^{2}$ \\
\hline Group & 165 & 1 & 165 & 0.060 & 0.812 & - & - \\
\hline Error(Group) & 27641 & 10 & 2764 & & & & \\
\hline Target & 93484 & 1 & 93484 & 59.12 & $<0.0001$ & $<0.0001$ & 0.86 \\
\hline Error(Target) & 15814 & 10 & 1581 & & & & \\
\hline Crossing & 18217 & 8 & 2277 & 12.05 & $<0.0001$ & $<0.0001$ & 0.55 \\
\hline Error(Crossing) & 15113 & 80 & 189 & & & & \\
\hline Group $\times$ Target & 1360 & 1 & 1360 & 0.86 & 0.376 & - & - \\
\hline Error (Group $\times$ Target) & 15814 & 10 & 1581 & & & & \\
\hline Group $\times$ Crossing & 3792 & 8 & 474 & 2.51 & $<0.025$ & 0.069 & - \\
\hline Error (Group × Crossing) & 15113 & 80 & 189 & & & & \\
\hline Target $\times$ Crossing & 10534 & 8 & 1317 & 8.76 & $<0.0001$ & $<0.0001$ & 0.47 \\
\hline Error (Target $\times$ Crossing) & 12029 & 80 & 150 & & & & \\
\hline Group $\times$ Target $\times$ Crossing & 1295 & 8 & 162 & 1.08 & 0.388 & - & - \\
\hline Error $($ Group $\times$ Target $\times$ Crossing) & 12029 & 80 & 150 & & & & \\
\hline
\end{tabular}


Fig. 3 Total (wet and dry) visibility (mean \pm standard error) of the bicyclist dummies and of the corresponding cycle crossings

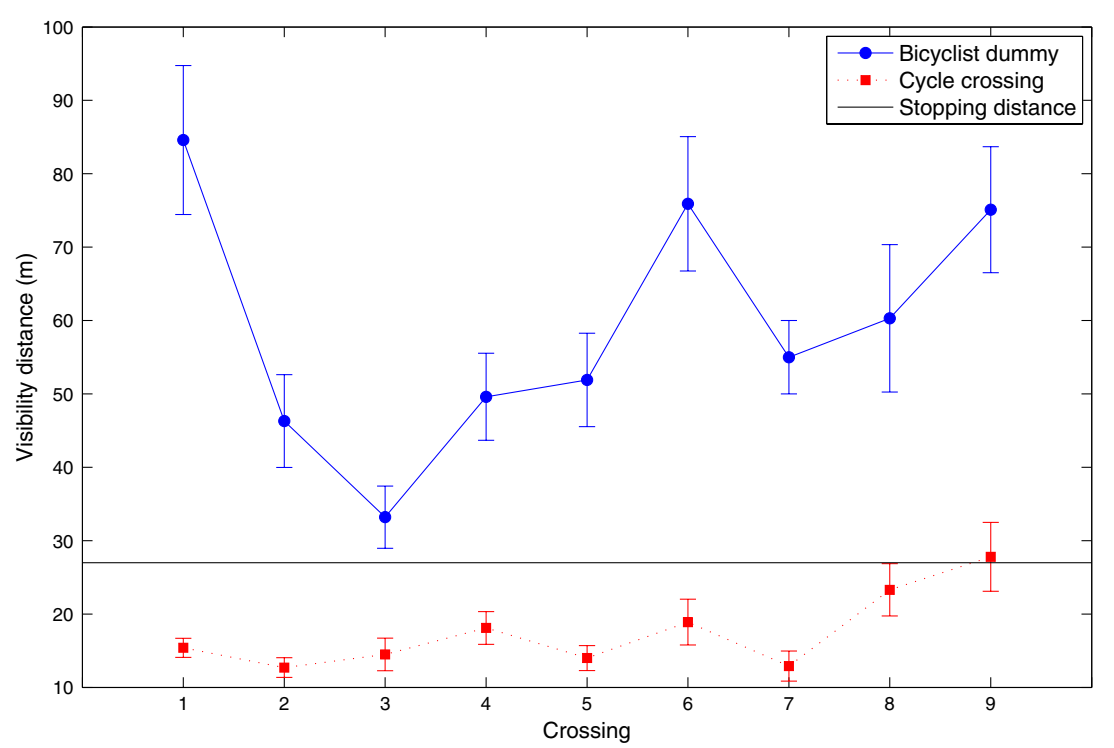

\section{Discussion}

In this field study, it was found that bicyclist dummies standing at cycle crossings as if they are about to cross the road are seen at a significantly longer distance than the cycle crossing markings at night-time. The results imply that the cycle crossing markings do not help the driver to become observant of the cycle crossing until the vehicle is very close to the crossing, where the driver might not be able to slow down or stop if a bicyclist suddenly appears. The average visibility distance of the cycle crossings was shorter than the stopping distance in eight out of the nine crossings, while the bicyclist dummies on average were seen at longer distances than the stopping distance at all crossings.

A wet road surface resulted in significantly shorter visibility distances of cycle crossings than a dry road surface. No such effect was found for the visibility distance of bicyclist dummies. A reasonable explanation is that since the bicyclist dummies were located on the side of the road, the background - which is strongly related to visibilitywas most often made up by lawns, buildings etc which are not much affected by wet weather. A wet road surface, on the other hand, often provides worse visibility conditions than a dry road (at night), because of specular reflection in the road surface.

The bicyclist dummies in the experiment were standing still and they had no retroreflective tags or bicycle lighting. In addition, the dummies were painted in a grey colour in order to minimize the contrast between the dummy and the background. The bicyclist dummies were thus a "worst case scenario" with regard to visibility. Motion, bright coloured clothing and the presence of lighting or retroreflective tags would probably increase the conspicuity of the bicyclists. One could thus argue that since the "worst case dummies" had a visibility distance longer than the stopping distance, the visibility distance of real bicyclists should be sufficient and that the visibility of the cycle crossing itself is of minor importance. However, since bicyclists move relatively fast and often are hidden behind buildings and shrubberies etc in urban areas, they may not come into sight until it is too late for the driver to stop. In these cases, the cycle crossing should help the driver to become aware that bicyclists might appear, especially if the traffic rules state that motorists should yield to bicyclists at cycle crossings, which has recently been proposed as a new rule by the Swedish Transport Agency [2]. Another notion is that the detectability could be considered as a "best case scenario", since the only task for the participants was to focus on finding the bicyclist dummies or cycle crossings, respectively.

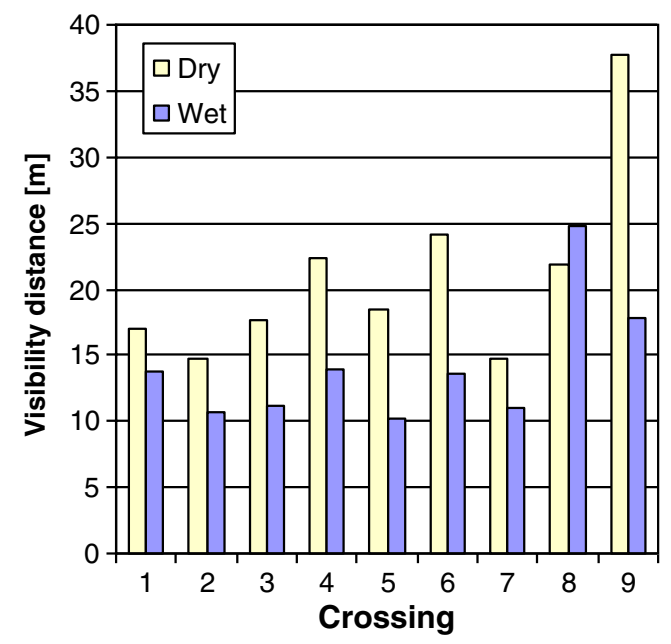

Fig. 4 Mean visibility of cycle crossings on wet and dry roads 


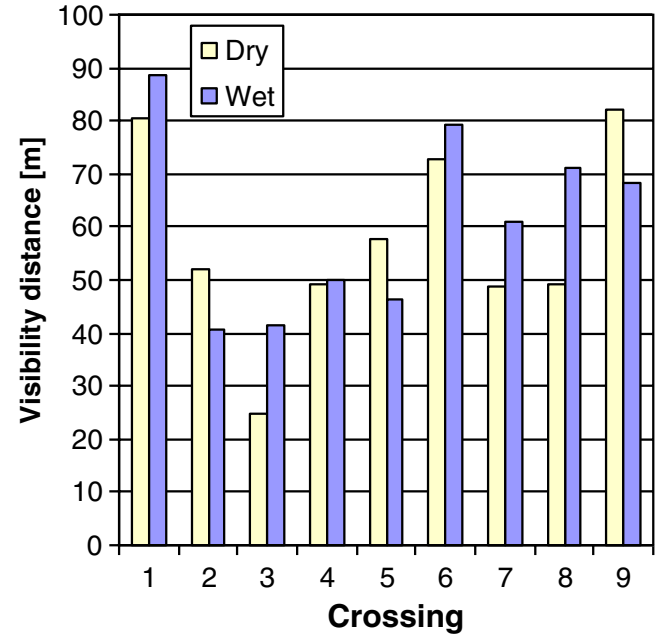

Fig. 5 Mean visibility of bicyclist dummies on wet and dry roads

All cycle crossings in the experiment were combined with a pedestrian crossing and so are most cycle crossings in Sweden. The visibility of a pedestrian crossing can be expected to be better than that of a cycle crossing, since the pedestrian crossing has larger road markings (wide white stripes) and also a road sign. The pedestrian crossing will probably increase the driver's attention but to what extent the pedestrian crossing will have an influence on the driver's preparedness for bicyclists is not known.

The study was carried out in real traffic with real cycle crossings, which means that the connection to reality was high. In order to obtain good experimental conditions, some precautions were made: The experiment was conducted late at night in order to reduce the influence from other vehicles (e.g. glare from oncoming traffic). The participants were not told in advance what they were about to look for, i.e. before the first run they were only told to look for bicyclist dummies. Cycle crossings were not mentioned at all, which means that the participants probably did not remember their location when they were told about the second part of the experiment (i.e. to look for cycle crossings). To minimize the familiarity of the crossings, the starting positions were altered and there was a break between the two parts of the experiment.

For practical reasons, the participants in the study were passengers and not drivers. This means that they could pay their full attention to the visibility task, which may have resulted in longer visibility distances than if they had been driving the car. However, the level of attention may have varied over time as well as between participants. Additionally, sitting in the back seat - which two thirds of the participants did - may result in somewhat shorter visibility distances than when sitting in the front seat. It is hard to estimate the size of these effects, but they are not believed to have any major impact on the main results, i.e. that there is a significant difference in visibility between cycle crossings and bicyclist dummies.

The number of participants in the study was relatively small (12 in total), but since the difference in visibility distance between bicyclist dummies and cycle crossings was very clear at all crossings, there is no reason to believe that the results had been different with more participants. However, it should be noted that the visibility varied a lot between different cycle crossings (both with and without bicyclist dummy). The cycle crossings included in the study differed in several ways with regard to street lighting, road width, background (complexity, brightness/luminance, presence/absence of light sources) etc, which probably explains the large differences in visibility. No clear relation between visibility and $\Delta E$ (for bicyclist dummies) or $C$ (for
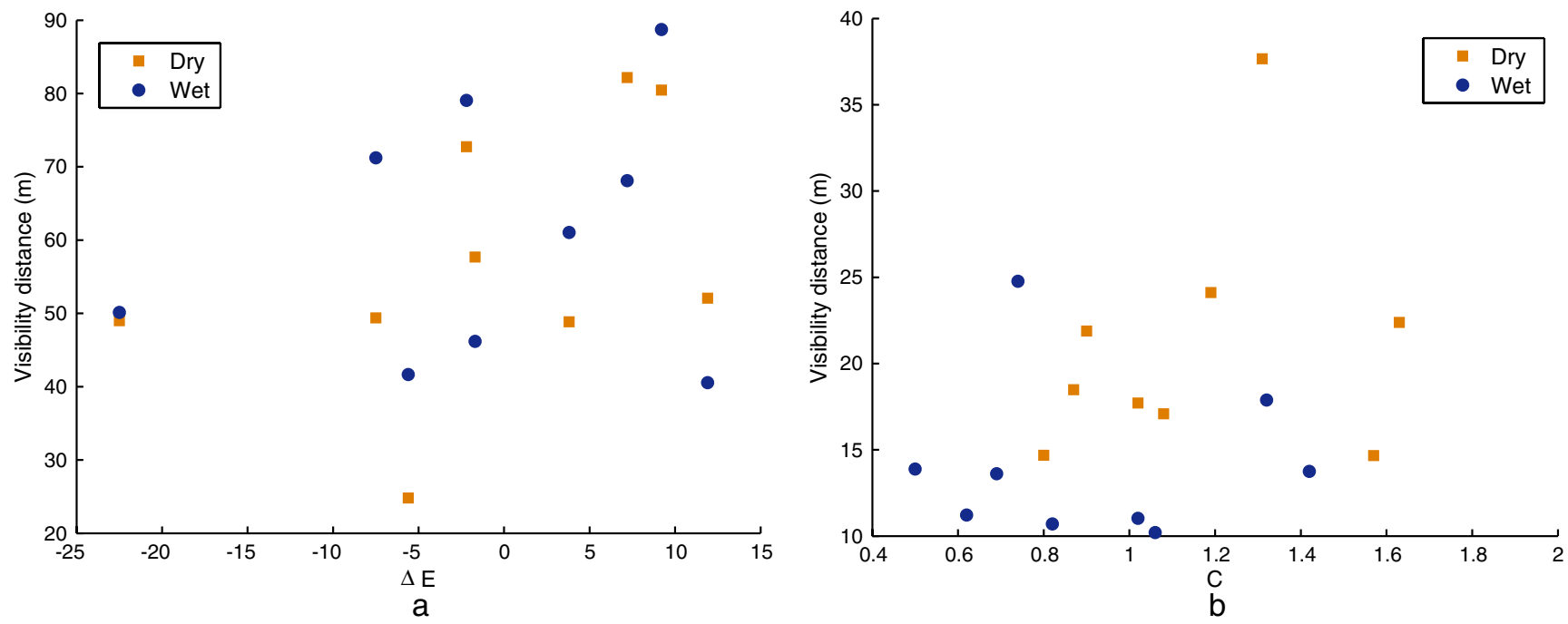

Fig. 6 Relation between $\Delta E$ and visibility distance to the bicyclist dummy (a) and relation between $C$ and visibility distance to the cycle crossing (b) 
cycle crossings) could be shown, which implies that other factors have an influence on the visibility. An example showing the influence of other factors is the relatively short visibility distance of bicyclist dummies at cycle crossing no. 3. (See Fig. 5). At this crossing, the bicyclist dummy was partly hidden behind a road sign for pedestrian crossing.

Literature on design and visibility of cycle crossings is limited. There are a few studies considering safety effects of coloured pavement markings at cycle crossing, with somewhat ambiguous results [11-13]. Sadek and colleagues have studied the effectiveness of green coloured cycle crossings [13]. Regarding visibility, about two thirds of the motorists did not think that the green bicycle lanes were visible at night. To our knowledge, no other results on visibility of cycle crossings exist in the literature. Therefore, a natural continuation of this study is to investigate how the visibility of cycle crossings can be improved and how the visibility is related to driving behaviour, e.g. speed and eye scanning behaviour. It would also be of interest to study the visibility of pedestrian crossings and its relationship to the ability to detect bicyclists. In a first step, we will study alternative designs of cycle crossings, with regard to visibility.

\section{Conclusion}

This field test showed that bicyclists were seen at longer distances than cycle crossings combined with pedestrian crossings at night-time. The cycle crossings were seen at shorter distances than the stopping distance when driving in $50 \mathrm{~km} / \mathrm{h}$. Cycle crossings were seen at significantly longer distances when the road surface was dry than when it was wet, while no such effect was seen for bicyclists. No advice on keeping or changing the priority rule for bicyclists and motorists at cycle crossings can be made exclusively from this study. Further research is recommended on how the visibility of cycle crossings can be improved and on how the visibility is related to driving behaviour.

Acknowledgements The study was funded by the Swedish Road Administration.
Open Access This article is distributed under the terms of the Creative Commons Attribution Noncommercial License which permits any noncommercial use, distribution, and reproduction in any medium, provided the original author(s) and source are credited.

\section{References}

1. Thulin H, Niska A (2009) Tema cykel - skadade cyklister: Analys baserad på sjukvårdsregistrerade skador i STRADA (Swedish). VTI report 644. Swedish National Road and Transport Research Institute. Linköping, Sweden

2. Nilsson N (2009) Förslag till nya trafikregler vid cykelöverfarter och på gångbanor (Swedish). TSV 2009:2856. Swedish Transport Agency. Borlänge, Sweden

3. Fors C, Lundkvist S-O (2009) Night-time traffic in urban areas. A literature review on road user aspects. VTI report 650A. Swedish National Road and Transport Research Institute. Linköping, Sweden

4. Lindahl E, Stenbäck I (1999) Provundersökning av cyklisters synbarhet i tätort oktober-november 1998 (Swedish). The Swedish Road Administration, Borlänge

5. Fors C, Nygårdhs S (2010) Trafikanters upplevda behov och problem i mörkertrafik i tätort. En fokusgruppsstudie med cyklister, äldre bilförare och äldre fotgängare (Swedish). VTI notat 5-2010. Swedish National Road and Transport Research Institute. Linköping, Sweden

6. Johansson Ö, Wanvik PO, Elvik R (2009) A new method for assessing the risk of accident associated with darkness. Accid Anal Prev 41:809-815

7. Schnell T, Aktan F, Lee Y-C (2003) Nighttime visibility and retroreflectance of pavement markings in dry, wet, and rainy conditions. Transp Res Rec 1824:144-155

8. Gibbons RB, Andersen C, Hankey J (2005) Wet night visibility of pavement markings: a static experiment. Transp Res Rec 1911:113-122

9. Vägverket and Svenska Kommunförbundet (2004) Vägar och gators utformning (Swedish). VV publication 2004:80. Borlänge, Sweden

10. NTF, Nationalföreningen för trafiksäkerhetens främjande: NTF Konsument. Frågor och svar. Hur räknar man ut reaktionssträckan? http:/www.ntf.se/konsument/fraga3187.asp. Accessed 16 February 2010

11. Hunter WW, Harkey DL, Stewart R, Birk ML (2000) Evaluation of blue bike-lane treatment in Portland, Oregon. Transp Res Rec 1705:107-115

12. Underlien Jensen S (2008) Safety effects of blue cycle crossings: a before-after study. Accid Anal Prev 40:742-750

13. Sadek A W, Dickason A, Kaplan J (2007). Effectiveness of a green high visibility bike lane and crossing treatment. TRB 86th annual meeting, Washington DC 